\title{
COMPOSITIONAL AND MORPHOLOGICAL EVALUATION OF EDIBLE SALTS: PRELIMINARY RESULTS
}

\author{
Stergiou C. ${ }^{1}$, Karageorgiou S. ${ }^{1}$, Theodoridou S. ${ }^{1}$, Giouri K. ${ }^{1}$, Papadopoulou \\ L. ${ }^{1}$ and Melfos V. ${ }^{1}$
}

${ }^{1}$ Aristotle University of Thessaloniki, School of Geology, Department of Mineralogy-PetrologyEconomic Geology, 54124, Thessaloniki, Greece, christer@geo.auth.gr,stamatik@geo.auth.gr, steltheo@geo.auth.gr,agiouri@geo.auth.gr,lambrini@geo.auth.gr,melfosv@geo.auth.gr

\begin{abstract}
Nutritional habits have as a result the uptake of the elemental content of various foods in the human body. Salt $(\mathrm{NaCl})$ constitutes an integral part of human diet needs. As a consequence, knowledge concerning the composition of edible salt is critical. The aim of the present study is to evaluate the components of 8 edible salt samples that are available in the Greek retail market. Samples were classified according to their color as follows: white (WS1, WS2), black (BS1, BS2), pink (PS1), red (RS1), blue (BLS1) and pale brown (BRS1). The research revealed that all samples mainly consist of $C l$ and Na. Himalayan Black Salt (BS2) also contains S, whereas the Hawaiian Red Salt (RS1) contains Fe. Additionally, most of the samples contain low levels of Al, Ca, K, $M g, P, S$, Si and $O$ as impurities. Concerning the morphological characteristics, salt particles appear irregular, rounded and in two cases as cubic crystals referring to the crystal structure of $\mathrm{NaCl}$. Backscattered images confirm the presence of other mineral phases besides $\mathrm{NaCl}$.
\end{abstract}

Keywords: Sea salt, Rock salt, Sodium chloride, Human consumption.

\section{Пєрí̇}

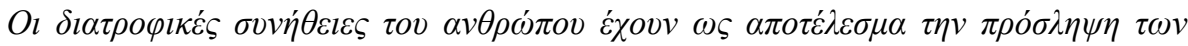

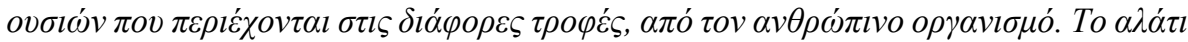

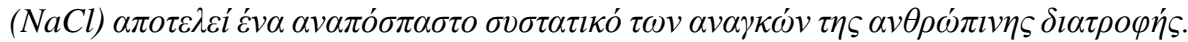

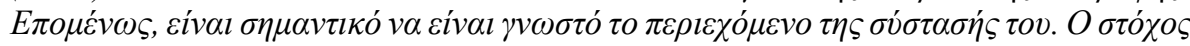

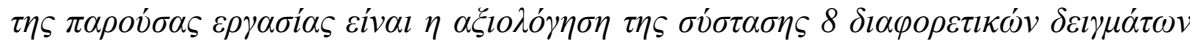

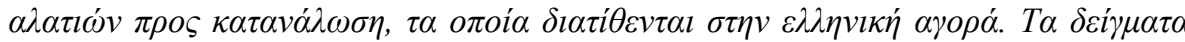

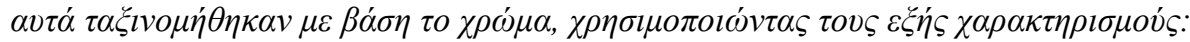

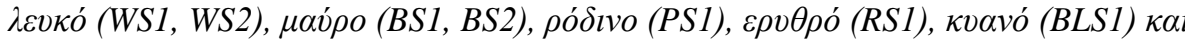

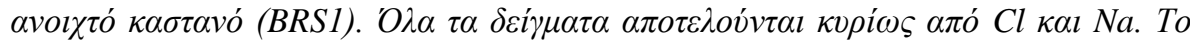

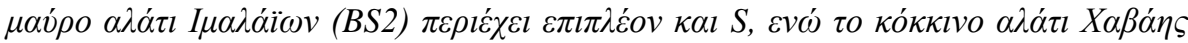

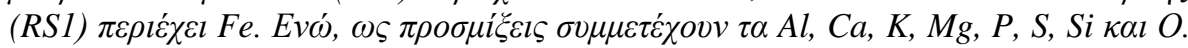

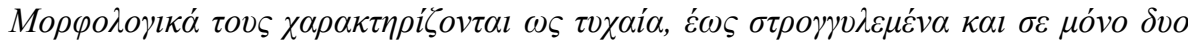

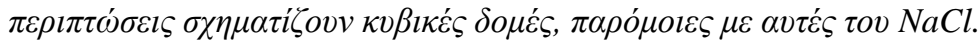

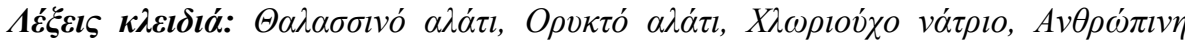
$\delta \iota \alpha \tau \rho \circ \varphi \dot{r}$ 


\section{Introduction}

The word salt relates to the ancient Greek word $\alpha \dot{\lambda} \varsigma$ (genitive: $\alpha \lambda \dot{c} \varsigma$ ). $A \lambda \varsigma$ means either "salt", the substance which enhances the flavour in food, or "sea" (Babiniotis, 2010). However, nowadays salt refers to any salty material despite its relation to the sea.

Edible salt $(\mathrm{NaCl})$ is worldwide the most commonly used food additive, providing improvement of taste and preservation of food. Its biological necessity lies on the fact that sodium and chlorine, the two main elements that it provides, are very important for the human body (Musaiger et al., 2008; Soylak et al., 2008; Cheraghali et al., 2010). Since food chain is a common pathway for human exposure to many elements, the analysis of food samples for their elemental concentration is very important and has been continuously performed (Haddy, 2006; Steinhauser et al., 2006; Tuzen and Soylak, 2007). The various properties of the chemical elements are essential for human life. However, when some elements are found in high concentrations, they can be considered as toxic. Edible salt may contain various chemical substances and due to its excessive use, information about its elemental content is critical (Zukowska and Biziuk, 2008; Zarei et al., 2011).

The aim of the present study is to determine the general and morphological characteristics of 8 different types of edible, refined and unrefined, salts available in the Greek retail market and to evaluate their mineralogical and chemical composition.

\section{Materials and Methods}

A variety of refined and unrefined edible salts was examined in this study. Eight pre-packed salt sa mples available in the Greek market were purchased, either directly from the market or from vendo rs. Salts were examined in their bulk form, since they are used for human consumption in the way $\mathrm{t}$ hey are packed.

\subsection{Sample Identification}

The salt samples that were studied represented various origin locations, grain sizes, particle shapes, colors, sources and prices. However, as presented in Table 1, they were classified according to the ir color since it has been probably affected by their composition (which will be further investigated ). Salts were classified in 6 groups: white (WS1, WS2), black (BS1, BS2), pink (PS1), red (RS1), b lue (BLS1) and pale brown (BRS1).

\subsection{Sample Analyses}

Elemental analyses of the salt samples, as well as their particle size and morphology, were evaluated with a JEOL JSM-840A scanning electron microscope (SEM) at the Electron Microscopy Laboratory in the Faculty of Sciences, Aristotle University of Thessaloniki. The microscope was equipped with an energy dispersive spectrometer (EDS) INCA 300, providing spot analyses. The samples were coated with carbon with an average thickness of $200 \mathrm{~A}^{\circ}$, using a vacuum evaporator JEOL-4X. The operating conditions were $20 \mathrm{kV}$ accelerating voltage and $0.4 \mathrm{~mA}$ beam current. Beam diameter was $1 \mu \mathrm{m}$ while the time of each measurement was $60 \mathrm{sec}$.

\section{Results and Discussion}

Organoleptic characteristics and some physical properties of all the salt samples are presented in Table 1. Samples represented 8 commercial types of edible salts, originating from 5 different locations. Half of them (samples WS1, WS2, BS1, RS1) are, essentially, products obtained by the evaporation of seawater when heated by the sun. The rest of the samples (BS2, PS1, BLS1, BRS1) are simply crystallized salts, mainly mineral deposits known as rock salts. Classification of the rock samples was based on their color, leading to 1 sample from each locality, with the exception of white and black, out of which 2 samples were recognized (WS1 and WS2 for white, BS1 and BS2 for 
black). Concerning their odor, only the Himalayan Black salt smelled like sulfur, while the Hawaiian Red Salt gave away a slightly earthy smell.

Table 1 - Organoleptic characteristics of the studied salt samples.

\begin{tabular}{|l|l|l|l|l|l|l|}
\hline Sample & $\begin{array}{l}\text { Commerci } \\
\text { al Type }\end{array}$ & \multicolumn{1}{|c|}{ Location } & Source & Color & Odor & \multicolumn{1}{|c|}{ Grain Size } \\
\hline WS1 & Table Salt & $\begin{array}{l}\text { Mediterranean } \\
\text { Sea }\end{array}$ & Sea Salt & White & None & $\begin{array}{l}\text { Very fine crystals } \\
\leq 1 \mathrm{~mm}\end{array}$ \\
\hline WS2 & $\begin{array}{l}\text { Fleur de } \\
\text { Sel }\end{array}$ & $\begin{array}{l}\text { Mediterranean } \\
\text { Sea }\end{array}$ & Sea Salt & White & None & $\begin{array}{l}\text { Small crystals } \\
\leq 2 \mathrm{~mm}\end{array}$ \\
\hline BS1 & $\begin{array}{l}\text { Hawaiian } \\
\text { Black Salt }\end{array}$ & Hawaii & Sea Salt & Black & None & $\begin{array}{l}\text { Very large } \\
\text { crystals 3-10 mm }\end{array}$ \\
\hline BS2 & $\begin{array}{l}\text { Himalayan } \\
\text { Black Salt }\end{array}$ & $\begin{array}{l}\text { Himalayas } \\
\text { India) }\end{array}$ & $\begin{array}{l}\text { Mineral } \\
\text { Salt }\end{array}$ & Black & Sulfur & $\begin{array}{l}\text { Very fine crystals } \\
\leq 1 \mathrm{~mm}\end{array}$ \\
\hline PS1 & $\begin{array}{l}\text { Himalayan } \\
\text { Pink Salt }\end{array}$ & Himalayas & $\begin{array}{l}\text { Mineral } \\
\text { Salt }\end{array}$ & Pink & None & $\begin{array}{l}\text { Small crystals } \\
\leq 2 \mathrm{~mm}\end{array}$ \\
\hline RS1 & $\begin{array}{l}\text { Hawaiian } \\
\text { Red Salt }\end{array}$ & Hawaii & Sea Salt & Red & $\begin{array}{l}\text { Slightly } \\
\text { earthy }\end{array}$ & $\begin{array}{l}\text { Large crystals } \\
2-3 \mathrm{~mm}\end{array}$ \\
\hline BLS1 & $\begin{array}{l}\text { Persian } \\
\text { Blue Salt }\end{array}$ & Iran & $\begin{array}{l}\text { Mineral } \\
\text { Salt }\end{array}$ & Blue & None & $\begin{array}{l}\text { Large crystals } \\
2-5 \mathrm{~mm}\end{array}$ \\
\hline BRS1 & Alpine salt & Austrian Alps & $\begin{array}{l}\text { Mineral } \\
\text { Salt }\end{array}$ & $\begin{array}{l}\text { Pale } \\
\text { Brown }\end{array}$ & None & $\begin{array}{l}\text { Large crystals } \\
1-3 \mathrm{~mm}\end{array}$ \\
\hline
\end{tabular}

Many variations were observed in the grain size of the salt samples, as presented in Table 1. Figure 1 illustrates grains of each one of the 8 salt samples that were studied. Images were taken under a ZEISS stereoscope. The common table salt (WS1) and the Himalayan Black salt (BS2) are recognized as the most fine grained, since their crystal size is $\leq 1 \mathrm{~mm}$. Small crystals are observed in the Fleur de Sel (WS2) and the Himalayan Pink salt (PS1), with their size not exceeding $2 \mathrm{~mm}$. The grain sizes of all of the other samples vary between 1 and $5 \mathrm{~mm}$. The only exception is the Hawaiian Black salt (BS2), since its impressively large and pyramid shaped crystals vary from 3 to $10 \mathrm{~mm}$ (Fig.1).
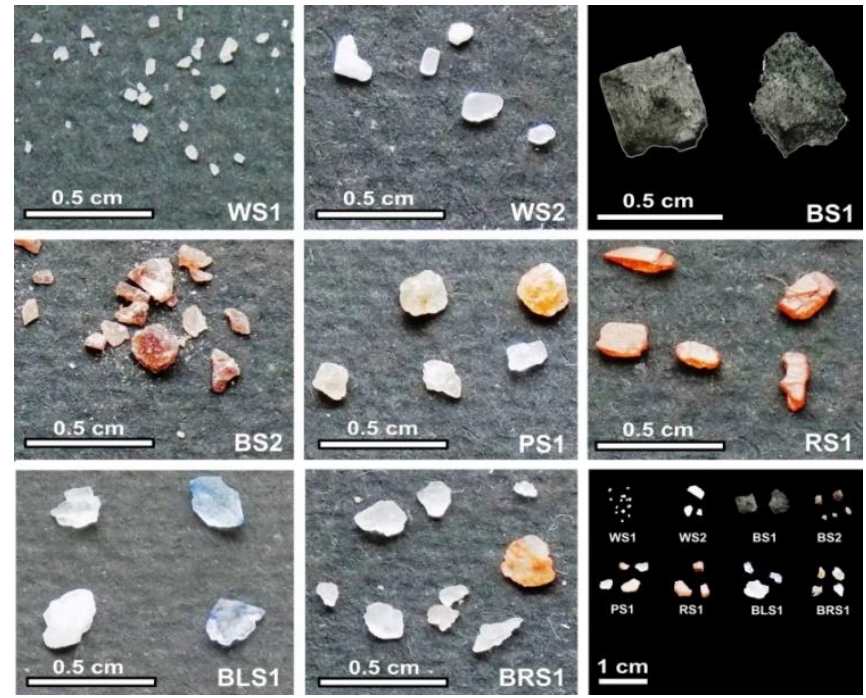

Figure 1 - Grains of the studied salt samples. 
Table 2 presents qualitative characteristics, as obtained by numerous spot analyses on the edible salt samples. It is concluded that all samples mainly consist of $\mathrm{Cl}$ and $\mathrm{Na}$. A differentiation was defined for the Himalayan Black Salt (sample BS2) since it also contains a sufficient amount of S, which can explain the odor of this sample, as indicated in Table 1 and Figure 2 . The same occurs for Fe, since it was defined as an abundant element in the Hawaiian Red Salt (sample RS1, Fig. 3). However, apart from their main elemental concentration, impurities were determined in most of the edible salts and they are mentioned in Table 2. The common Mediterranean Sea table salt and the Alpine salt were identified as the purest ones, since they contained no impurities. On the other hand, Himalayan Black salt (BS2) and Persian Blue salt (BLS1) comprise more impurities than the rest of the samples (Table 2). It should also be mentioned that oxygen was determined in the composition of all the edible salts. Thus, further investigation is required in order to define the mineral phases in which oxygen participates.

Table 2 - Qualitative characteristics of the studied salt samples.

\begin{tabular}{|l|l|l|l|l|l|}
\hline \multicolumn{1}{|c|}{ Sample } & \multicolumn{1}{c|}{ Cl } & Fe & \multicolumn{1}{|c|}{ Na } & \multicolumn{1}{|c|}{ S } & \multicolumn{1}{|c|}{ Impurities } \\
\hline WS1 & + & & + & & - \\
\hline WS2 & + & & + & & $\mathrm{Ca}, \mathrm{Mg}, \mathrm{S}$ \\
\hline $\mathrm{BS} 1$ & + & & + & & $\mathrm{K}$ \\
\hline BS2 & + & & + & + & $\mathrm{Al}, \mathrm{Ca}, \mathrm{Fe}, \mathrm{K}, \mathrm{Mg}, \mathrm{P}$ \\
\hline PS1 & + & & + & & $\mathrm{K}, \mathrm{Mg}, \mathrm{S}$ \\
\hline RS1 & + & + & + & & $\mathrm{Al}, \mathrm{Ca}, \mathrm{Mg}, \mathrm{S}, \mathrm{Si}$ \\
\hline BLS1 & + & & + & & $\mathrm{Ca}, \mathrm{K}$ \\
\hline BRS1 & + & & + & & - \\
\hline
\end{tabular}

The results obtained by the elemental analyses of the studied samples are presented in Table 3 . The most abundant elements are $\mathrm{Cl}$ and $\mathrm{Na}$, as revealed by their mean values (in weight \%) which are the highest ones (67.1 and 28.8, respectively). They take part in the composition of all the salt samples and the range of their percentage is 14.1-95.8\% for $\mathrm{Cl}$ and 4.2-44.3\% for $\mathrm{Na}$. As mentioned above, $\mathrm{S}$ and $\mathrm{Fe}$ are abundant in samples BS2 and RS1, respectively. Moreover, they are present in lower amounts in some other samples (Table 2). Overall, $\mathrm{S}$ ranges from $0.7 \%$ to $65.7 \%$ with its mean value reaching up to $9.7 \%$, while Fe ranges from $1.2 \%$ to $43.9 \%$ with a mean of $8.0 \%$.

SEM observations of representative salt samples with their corresponding spectrums are illustrated in Figures 2 and 3. All samples consist of irregular, rounded particles with sizes ranging from $2 \mathrm{~mm}$ to less than $500 \mu \mathrm{m}$. In the black samples of Himalayan (BS1) and Hawaiian (BS2) salts, cubic crystals are present with cubic blemishes referring to the crystal shape of $\mathrm{NaCl}$ (face-centered cubic structure). Backscattered images show the presence of different mineral phases (dark grey areas) both on the surface of the salt particles (samples BS1 and PS1) as well as individual grains (sample $\mathrm{RS} 1$, lower left side), pointing to the existence of other mineral phases besides $\mathrm{NaCl}$, as determined by EDS analyses. These mineral phases will be determined through further investigation.

The concentrations of all other elements are relatively low, since they are present as impurities. The next predominant elements are $\mathrm{K}$ and $\mathrm{Ca}$ and that were determined in 4 samples. The range of their percentage is $1.3-50.7 \%$ for $\mathrm{K}$ and $1.0-26.5 \%$ for $\mathrm{Ca}$, while their corresponding mean values are $14.5 \%$ and $8.6 \%$. Magnesium was determined in 4 samples with a range of $1.5-11.8 \%$ and a mean value of $4.5 \%$. The percentage of $\mathrm{Al}$ ranges from $1.0 \%$ to $2.7 \%$ in 2 samples, with a mean of $1.7 \%$. In only 1 sample (RS1) Si was determined, with a range of $1.3-2.7 \%$ and a mean value of $2.0 \%$. Finally, it should be noted that in 1 sample (BS2) and in only 1 spot analysis, $0.9 \%$ of $\mathrm{P}$ was determined. 
Table 3 - Results of the elemental analysis of the studied edible salts and notable samples.

\begin{tabular}{|l|l|l|l|l|l|}
\hline Element & $\begin{array}{c}\text { Min } \\
\text { Weight \%) }\end{array}$ & $\begin{array}{c}\text { Max } \\
(\text { Weight \%) }\end{array}$ & $\begin{array}{c}\text { Mean } \\
(\text { Weight \%) }\end{array}$ & $\begin{array}{c}\text { Sample with } \\
\text { Lower Percentage }\end{array}$ & $\begin{array}{c}\text { Sample with } \\
\text { Higher Percentage }\end{array}$ \\
\hline Al & 1.0 & 2.7 & 1.7 & RS1 & BS2 \\
\hline $\mathbf{C a}$ & 1.0 & 26.5 & 8.6 & BLS1 & WS2 \\
\hline $\mathbf{C l}$ & 14.1 & 95.8 & 67.1 & BS1 & BS1 \\
\hline $\mathbf{F e}$ & 1.2 & 43.9 & 8.0 & RS1 & RS1 \\
\hline $\mathbf{K}$ & 1.3 & 50.7 & 14.5 & BS1 & BLS1 \\
\hline $\mathbf{M g}$ & 1.5 & 11.8 & 4.5 & WS2 & BS2 \\
\hline $\mathbf{N a}$ & 4.2 & 44.3 & 28.8 & BS1 & WS1 \\
\hline $\mathbf{P}$ & 0.9 & 0.9 & 0.9 & BS2 & BS2 \\
\hline $\mathbf{S}$ & 0.7 & 65.7 & 9.7 & BS1 & RS1 \\
\hline $\mathbf{S i}$ & 1.3 & 2.7 & 2.0 & RS1 & \\
\hline
\end{tabular}

The lowest and highest percentage of some elements was observed in the same sample (Table 3). T his is reasonable in the case of $\mathrm{P}$ and $\mathrm{Si}$, since they were detected in only 1 sample. Although $\mathrm{Cl}$ is one of the main components of the salt samples, its minimum and maximum values are observed in the same sample (BS1). Despite the fact that they were determined in almost half of the samples, 1 owest and highest contents of Fe and $\mathrm{S}$ were determined in samples RS1 and BS1, respectively ( $\mathrm{Fi}$ g. 2, 3). Sample BS1 contains the lowest $\mathrm{K}$ and $\mathrm{Na}$ values, while the highest values were observed in sample BLS1 and WS1, respectively. The lowest amount of Al was observed in sample RS1 and the highest in sample BS2. The Mg content ranges from $1.5 \mathrm{wt} \%$ in the sample WS2 to $11.8 \mathrm{wt} \% \mathrm{i}$ $\mathrm{n}$ the sample BS2. As for Ca, its lowest and highest values were determined in samples BLS1 (1.0 wt $\%)$ and WS2 (26.5 wt $\%)$, respectively.
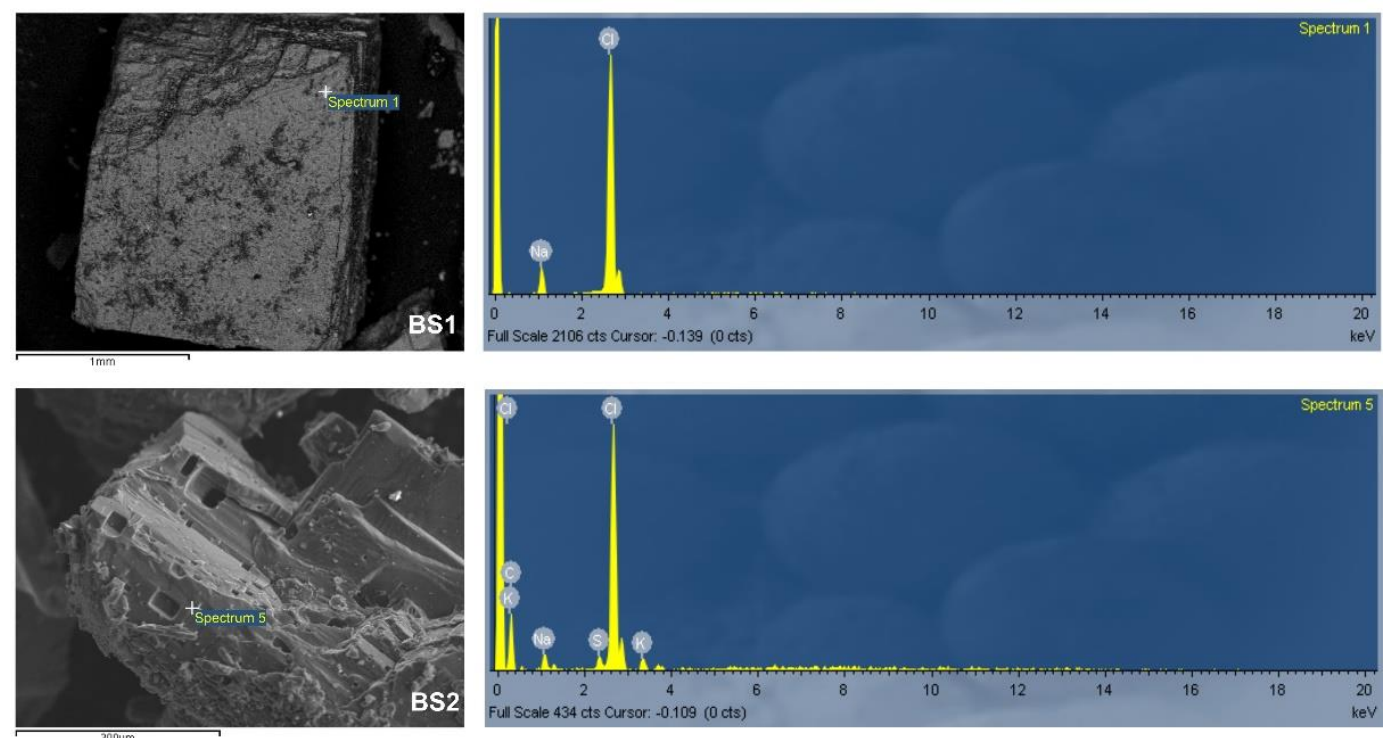

Figure 2 - SEM microphotographs of the studied samples, with representative X-ray spectrums. Sample BS1: backscattered image; BS2: secondary image. 

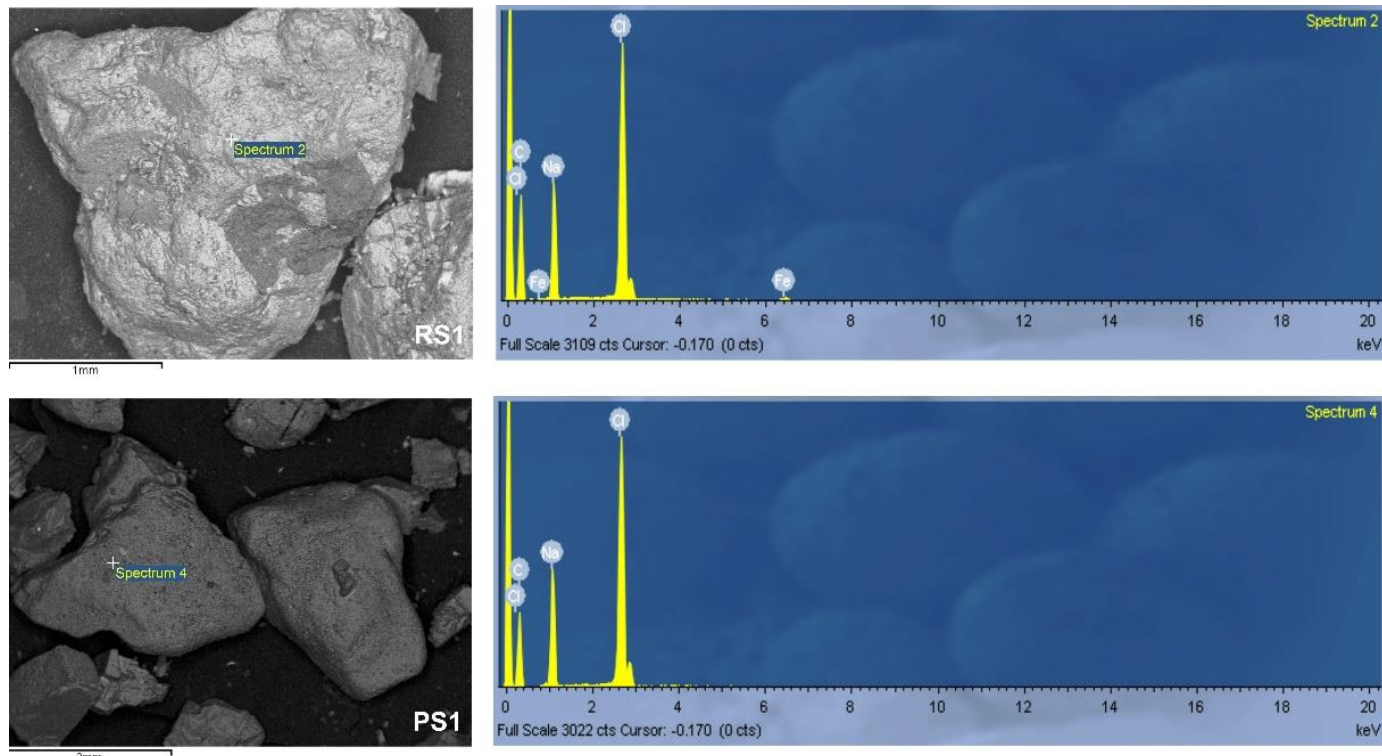

Figure 3 - SEM microphotographs of the studied samples, with representive X-ray spectrums. Samples RS1 and PS1: backscattered images.

\section{Conclusions}

The studied samples represent 8 commercial types of edible salts, of 6 different colors and originating from 5 different locations (Mediterranean Sea, Hawaii, Himalayas, Iran and Austrian Alps). Four samples include sea salts and four samples are rock salts. The size of their grains varies from very fine $(\leq 1 \mathrm{~mm})$ to very large $(10 \mathrm{~mm})$.

Bulk chemical analyses of the samples revealed that all of them consist mainly of $\mathrm{Cl}$ and $\mathrm{Na}$. Additionally, samples BS2 and RS1 contain sufficient amounts of S and Fe, respectively. Apart from their main chemical composition, most of the edible salt samples contain low levels of $\mathrm{Al}, \mathrm{Ca}, \mathrm{K}$, $\mathrm{Mg}, \mathrm{P}, \mathrm{S}, \mathrm{Si}$ and $\mathrm{O}$ as impurities.

Concerning morphological characteristics, salt grains in all samples appear irregular and rounded with sizes ranging from $<2 \mu \mathrm{m}$ to $2 \mathrm{~mm}$. Backscattered images certify the existence of different mineral phases other than $\mathrm{NaCl}$.

However, the research is in progress since a more detailed evaluation of the composition of the salt samples is required, especially concerning the trace elements that they may comprise.

\section{References}

Babiniotis, G., 2010. Etymological Dictionary of the Modern Greek Language: History of Words, Athens, Lexicology Centre Ltd, 1652 pp.

Cheraghali, A.M., Kobarfard, F. and Faeizy, N., 2010. Heavy metals contamination of table salt consumed in Iran, Iranian Journal of Pharmaceutical Research, 9(2), 129-132.

Haddy, F.J., 2006. Role of dietary salt in hypertension, Life Sciences, 79, 1585-1592.

Musaiger, A.O., Al-jedah, J.S. and D'souza, R., 2008. Occurrence of contaminants in foods commonly consumed in Bahrain, Food Control, 19(9), 854-861.

Soylak, M., Peker, D. and Turkoglu, O., 2008. Heavy metal contents of refined and unrefined table salts from Turkey, Egypt and Greece, Environmental Monitoring and Assessment, 143, 267-272. 
Steinhauser, G., Sterba, J.H., Poljanc, K., Bichler, M. and Buchtela, K., 2006. Trace elements in rock salt and their bioavailability estimated from solubility in acid, Journal of Trace Elements in Medicine and Biology, 20, 143-153.

Tuzen, M. and Soylak, M., 2007. Evaluation of trace element contents in canned foods marketed from Turkey, Food Chemistry, 102, 1089-1095.

Zarei, M., Eskandari, M.H. and Pakfetrat, S., 2011. Determination of heavy metals content of refined table salts, American-Eurasian, Journal of Toxicological Sciences, 3(2), 59-62.

Zukowska, J. and Biziuk, M., 2008. Methodological evaluation of method for dietary heavy metal intake, Journal of Food Sciences, 73(2), R21-R29. 